\title{
Numerical Examination on the Effect of Internal Fluid Presssure on the Hydrodynamic Response of a Marine Riser
}

\begin{abstract}
Marine risers are long slender structures which links the floating vessel on the sea surface and its manifold on the sea bottom. It acts as a transportation means for the hydrocarbon resources underneath the sea bed. A riser mainly undergoes hydrodynamic loading which leads to Vortex induced vibrations (VIV) or Flow induced vibrations. These are motions induced on bodies interacting with an external fluid flow producing periodic irregularities on the flow which leads to fatigue damage of offshore oil exploration and production risers. Therefore, suppressing of VIV by providing helical strakes, fairings etc. is necessary in order to reduce the fatigue damage of risers due to hydrodynamic loading. The present paper deals with the numerical study on the response of a marine riserdue to the effect of internalfluid pressure. The initial work is carried out in ANSYS ICEM CFD software. The CFD solution after analysis is obtained from ANSYS FLUENT. The hydrodynamic effects like lift and drag forces along with motion responses is obtained.
\end{abstract}

Sarga

Keywords-Vortex induced vibrations, Computational Fluid Dynamics, Internal fluid pressure, Structural response, Hydrodynamic loading, Cross flow vibration, Inline vibration.

\section{INTRODUCTION}

A marine riser is basically a slender structure used for transporting crude oil, natural gas and other undersea economic resources in the offshore structural system. It can be a single pipeline or a group of flow lines which is assembled as an integral unit for the production riser system. It is inevitably subjected to severe environmental forces resulting from currents and waves. Being an extensible and flexible tubular structure, as ocean recourse exploration expands into deep waters, it becomes much longer and slenderer. Then the dynamics start exhibiting new dynamic features which requires more careful analysis for the safety of offshore operations. So in order to achieve reliable performance, these risers must be designed carefully with respect to the different types of loads that are expected to affect them. Different types of load occurring on the marine risers mainly include hydrodynamic loading known as flow induced vibrations [4]. Thereby, it is very important to perform the dynamic analysis of the structure to enhance the performance of these structures throughout lifetime.

A riser system can be installed for tension leg platform

(TLP), floating production, storage and offloading unit (FPSO) as shown in Fig.1.A tension leg platform is a buoyant

Revised Manuscript Received on September 22, 2019.

Sarga, Civil Engineering Department, SCMS School of Engineering \& Technology, Karukutty,Ernakulam,India.sargapr@gmail.com platform held in place by a mooring system. Mooring system is a set of tension legs or tendons attached to the platform and connected to foundation on the sea floor.FPSO unit is a floating vessel which receives hydrocarbons from nearby platforms or subsea template, processes them, and stores oil until it is offloaded to a tanker. As we know that the depth of sea can extend from several hundred to a couple thousand feet, there are chances of collapse and buckling of a riser by its own weight. To prevent this, the riser is subjected to a constant top tension. Also, to reduce the weight of flexible risers in water, buoyancy modules made of epoxy resin, micro glass etc. having a specific weight of $0.35-0.45$ dimensioned for depths of 500-2000 meters are attached along the tube to provide a net buoyancy of $500-2000 \mathrm{~kg}$. These buoys make the riser neutrally, negatively or positively buoyant depending on the applications.

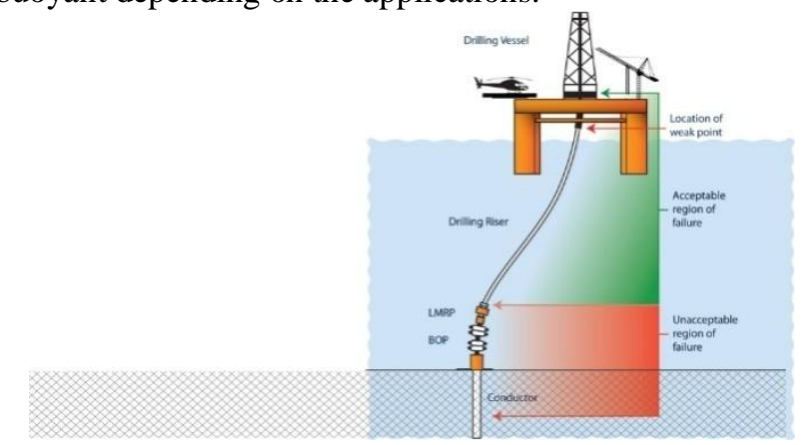

Fig.1 Drilling Riser connected to tension leg platform

The vortex shedding analysis can be studied both numerically and experimentally. Experimental studies show greater rate of accuracy but is tedious and time consuming. Mao Liangjie studied the vortex induced vibration of a riser under shear flow by means of a towing tank experiment wherein analysis of inline and cross flow vibrations of a riser was analysed using a Fibre Bragg grating sensor. Similarly, previous studies in the same area mainly focused on mass and stiffness ratios on the maximum amplitude response of the riser [2].Sup Hong mathematically formulated the internal flow effects of an underwater flexible riser by varying the mass density and internal flow velocity. Further, study of risers subjected to internal pressure was studied wherein the critical riser length for which instability may occur was determined for different end conditions [1].Shuai Yuan developed a theoretical model based on principle of virtual work for determining stresses and deformations of the riser pipe subjected to low internal pressure and the results were compared with the ones from FEM using ABAQUS. 


\section{II . FLOW INDUCED VIBRATION}

The loads on risers between a floater and the seabed or between two floaters are determined by the vessel motions, direct wave loads and current loads. Global loads and fatigue life of risers are often governed by Vortex Induced Vibrations (VIV), also called as Flow induced vibrations. Fig.2 shows an elicited pattern of vortices behind a cylinder. When slender marine structures like risers, free spanning pipelines and mooring lines are exposed to a current flow, they experience oscillations or vibrations caused by the shedding of vortices around the structure. VIV plays an important role in determining the lifespan of marine risers. Flexible risers are subjected to shear and oscillatory flows due to currents and waves and also due to intensity and direction changes according to water depth. The vortices generated due to these oscillations create lift and drag forces which cause excitation of the structure. These are called as Vortex Induced Vibrations. It is basically a Fluid structure interaction phenomenon wherein motions are generated when the body interacts with an external fluid flow. Best example of FSI phenomenon is the failure of Tacoma Narrows Bridge in Washington during the year 1940, wherein the bridge twisted and vibrated violently under a wind speed of $64 \mathrm{kmph}$ leading to collapse of the structure. VIV cause vibrations of high amplitudes at frequency near to the natural frequency of the member. When the vortex shedding frequency becomes equal to the natural frequency, resonance occurs which is known as lock-in. In the case of long flexible cylinders in shear flow, at each span wise location, the lock-in condition is established when the local vortex shedding frequency coincides with the local cross flow vibration frequency. The flow is known to excite the structure in lock-in region whereas it generally damps the structural vibrations in the non-lock-in region. Thereby, we can say that VIV can lead to fatigue damage in vibrating structures, which makes it an important issue in the design of bridges, chimney stacks and marine riser pipes.

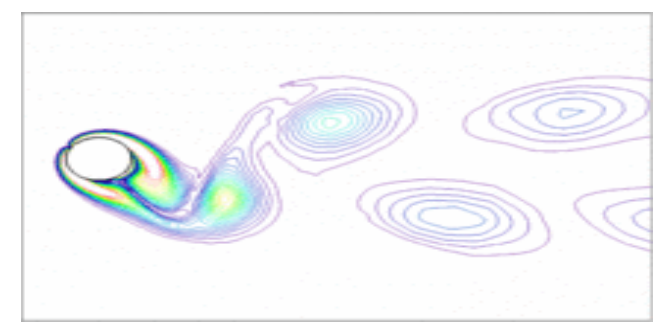

\section{NEED FOR NUMERICAL STUDY}

Several experimental studies on the VIV of a marine riser showed that a detailed pattern of vortex shedding could not be established. Particle Image Velocimetry (PIV) method is an optical method commonly used to obtain instantaneous velocity measurements and other fluid properties. But the method is known to be prohibitively expensive. Thereby, need arises for numerical methods. RANS based CFD methods have emerged as powerful tool for generating solutions for fluid flows with and without solid interaction. In this study, a marine riser is numerically analyzed for four different pressures.

\section{METHODOLOGY}

\section{D riser withinternal fluid pressure variation}

The present study addresses the vortex induced vibrations of a marine riser when it is given motion in both inline and cross flow directions. The riser model is analyzed using CFD by giving four different internal pressures in the range of $50-80 \mathrm{~Pa}$. Riser model having a diameter of $0.076 \mathrm{~m}$ with a Reynolds number of $3.8 \times 104$ is modeled and meshed in ANSYS ICEM CFD and ANSYS Fluent. A uniform flow velocity of $0.5 \mathrm{~m} / \mathrm{s}$ with a reduced velocity of 5 is maintained throughout the study [3].The riser model specifications are given in Table I.

TABLE I

RISERMODELSPECIFICATIONS

\begin{tabular}{|l|l|l|}
\hline Properties & Values & Units \\
\hline Diameter $(D)$ & 0.076 & $\mathrm{~m}$ \\
\hline Aspect ratio $(L / D)$ & 13.12 & - \\
\hline Flow velocity $(V)$ & 0.5 & $\mathrm{~m} / \mathrm{s}$ \\
\hline $\begin{array}{l}\text { Reynolds Number } \\
(\text { Re })\end{array}$ & $3.8 \mathrm{x}$ & - \\
\hline Mass ratio $\left(m^{*}\right)$ & 0.66 & - \\
\hline Strouhals number $(\mathrm{St})$ & 0.2 & - \\
\hline
\end{tabular}

In this study, the riser is kept inside a fluid domain having a length of 40D and a width of 20D.Th riser is located at 10D away from the inlet boundary. A dense mesh as seen in Fig.5 is created near to the cylinder in order to capture the effect of vortex shedding or Von Karman Street eddies at the wake explicitly. In Fig.5, it can be seen that inner surface of the riser is also meshed so that varying internal surface pressures can be applied.

The riser model here is considered as a two way FSI phenomenon. Flow around the cylinder is modelled using transient incompressible Navier-Stokes equation. The equations are solved numerically to obtain the hydrodynamic forces acting on the riser.RANS based solver with k- $\omega$ SST is use as the turbulence model.RANS equations are equations of motion for fluid flow. They are time averaged, primarily used to describe turbulent flows. Also, k- $\omega$ SST turbulence model is a two equation eddy viscosity model employed to determine the Reynolds stresses. The use of k- $\omega$ formulation in the inner parts of the boundary layer makes the model directly usable all the way through the viscous sub layer, thereby it is mainly used as low Reynolds number turbulence model without any extra damping functions. Two different fluids namely water as fluid 1 and kerosene liquid (petroleum product) as fluid 2 was taken. Pressure-velocity coupling scheme was taken as fractional time step. Also, Non-Iterative time advancement scheme was taken for transient formulation. Least squared cell based scheme as gradient along with second order upwind was used for spatial discretization.

Different boundary
Published By:
Blue Eyes Intelligence Engineering
\& Sciences Publication


conditions were given to riser as shown in Table II.

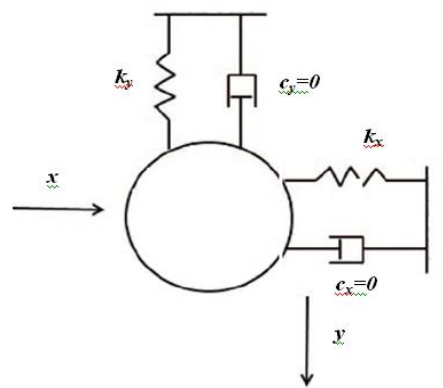

Fig.3Riser given TDOF condition

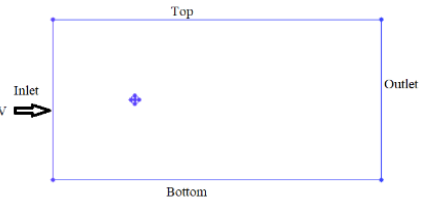

$\underset{\text { R15.0 }}{\text { ANSYS }}$

Fig. 4 Computational domain

TABLE II

BOUNDARY CONDITIONS For THE MODEL

\begin{tabular}{|l|l|}
\hline Parameters & $\begin{array}{l}\text { Boundary } \\
\text { condition }\end{array}$ \\
\hline Top & Symmetry \\
\hline Bottom & Symmetry \\
\hline Inlet & $\begin{array}{l}\text { Velocity- } \\
\text { inlet }\end{array}$ \\
\hline Outlet & $\begin{array}{l}\text { Pressure } \\
\text { outlet }\end{array}$ \\
\hline Riser & $\begin{array}{l}\text { Wall, No } \\
\text { slip }\end{array}$ \\
\hline
\end{tabular}

Next, under dynamic mesh different mesh zones are created and their equations of motion are solved in a 6DOF solver. A user defined function compiled in $\mathrm{C}$ programming language is hooked to the cylinder surface mesh curve so as to provide motion to the cylinder in both inline and cross flow directions. Smoothing and Remeshing are the mesh methods mainly applied to the cylinder. Finally, the model is solved for hydrodynamic effects like lift and drag forces. Also the motion history of the cylinder along inline (IL) and cross flow (CF) directions can be obtained.

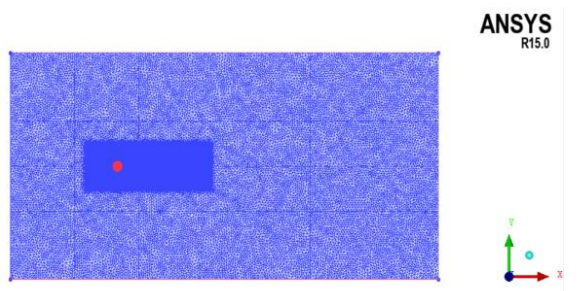

Fig.52D computational mesh created in ICEM CFD

\section{RESULTS AND DISCUSSION}

In this paper, a $2 \mathrm{D}$ riser was analyzed numerically by means of ANSYS ICEM CFD and ANSYS FLUENT.

A TDOF riser with varying internal fluid pressure is analyzed here. The pressure distribution around the cylinder is shown with the help of pressure contours as seen in Fig.6.The hydrodynamic characteristics of the riser like lift and drag forces were studied.Also,the motion response of the cylinder along inline and cross flow directions were studied and is indicated by $\mathrm{X} / \mathrm{D}$ and $\mathrm{Y} / \mathrm{D}$, where $\mathrm{X}$ represents the maximum amplitude of the riser along inline direction and $\mathrm{Y}$ represents the maximum amplitude of the riser along cross flow direction, D represents the diameter of the cylinder.

A. With $50 \mathrm{~Pa}$ internal pressure

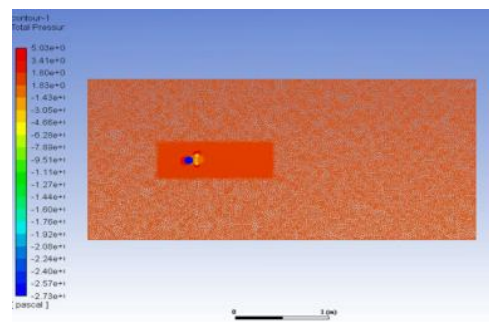

Fig. 6Pressure contours of cylinder with internal pressure of $50 \mathrm{~Pa}$

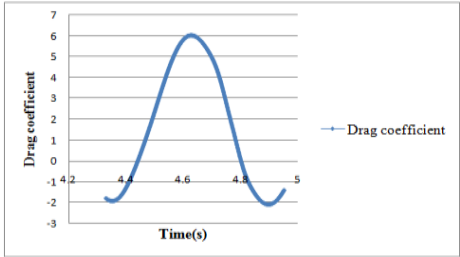

Fig. 7CD of cylinder

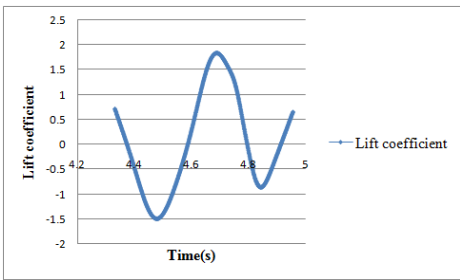

Fig. $8 \mathrm{C}_{\mathrm{L}}$ of riser

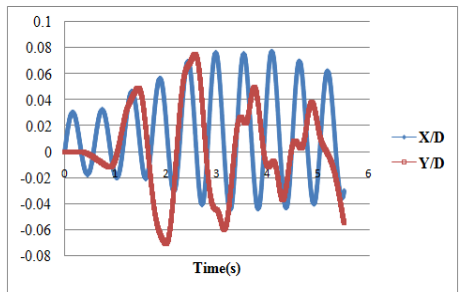

Fig. 9Motion response history of riser

B. With $60 \mathrm{~Pa}$ internal pressure

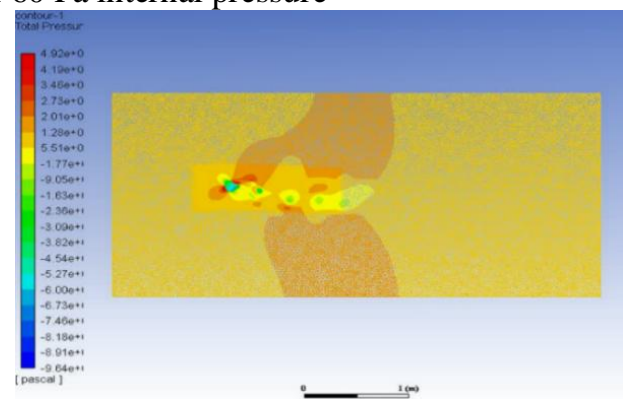

Fig. 10Pressure contours of cylinder with internal pressure of $60 \mathrm{~Pa}$ 


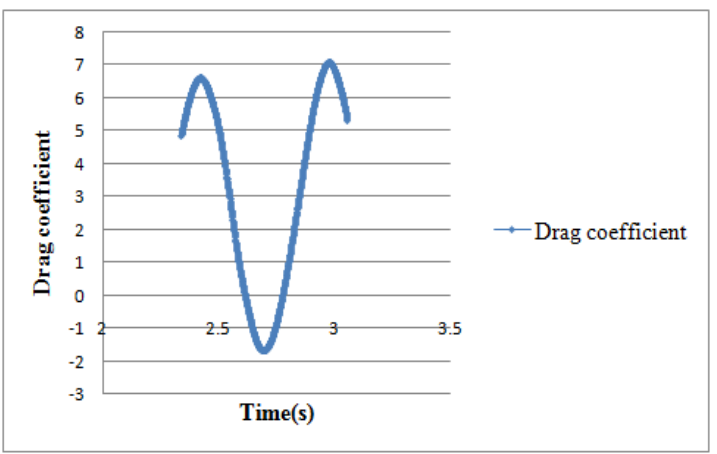

Fig. 11CD of cylinder

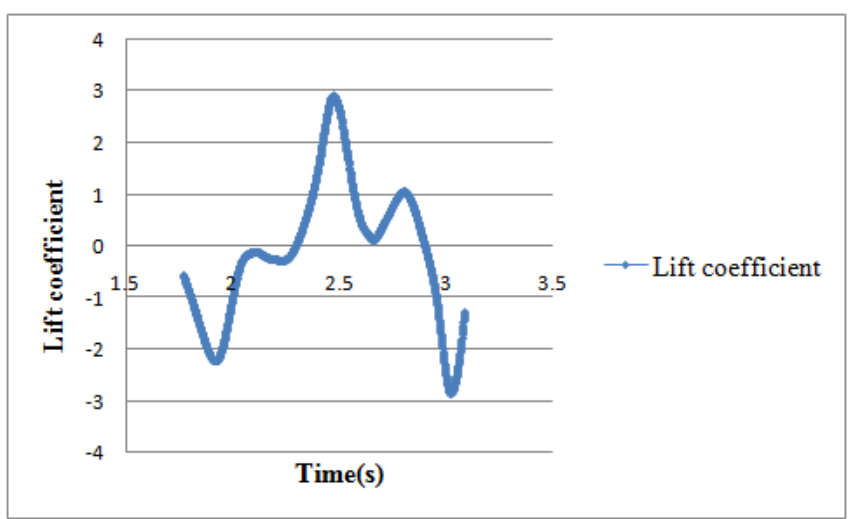

Fig. 12CL of riser

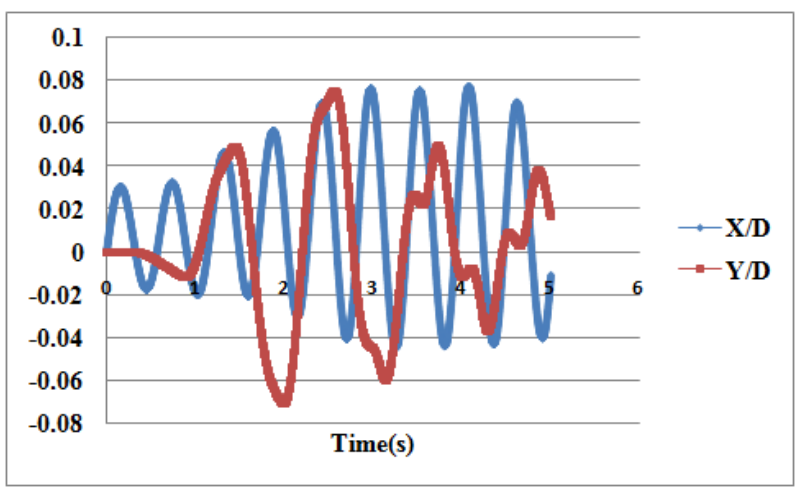

Fig. 13Motion response history of riser

C. With $70 \mathrm{~Pa}$ internal pressure

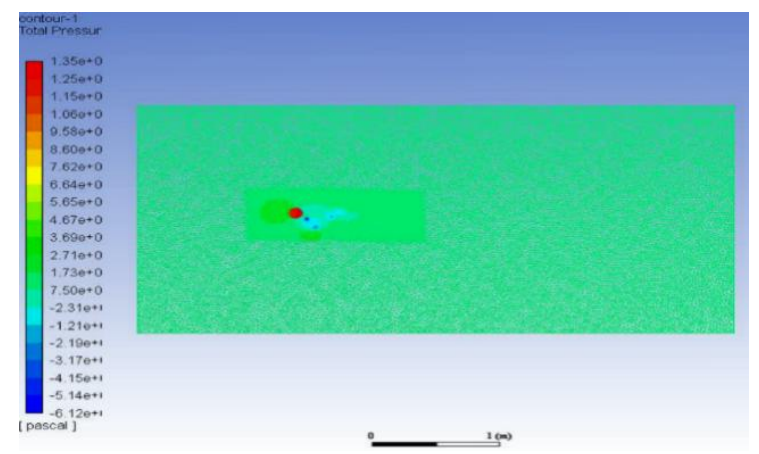

Fig. 13 Pressure contours of cylinder with internal pressure of $70 \mathrm{~Pa}$

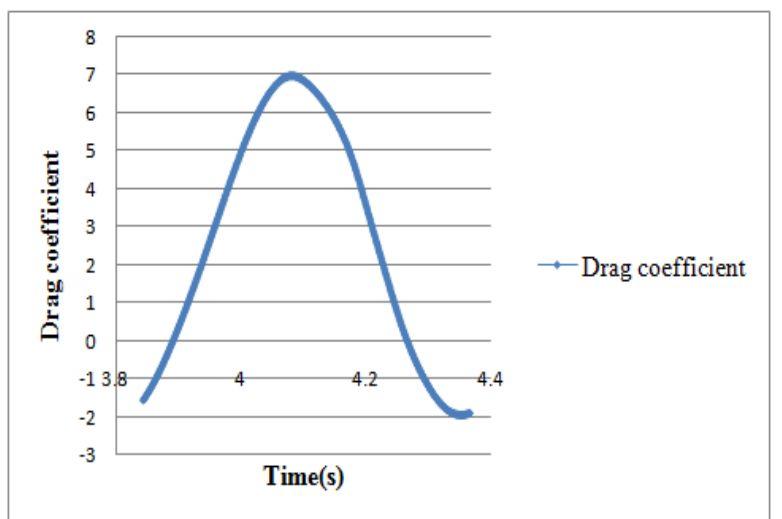

Fig. 14 CD of cylinder

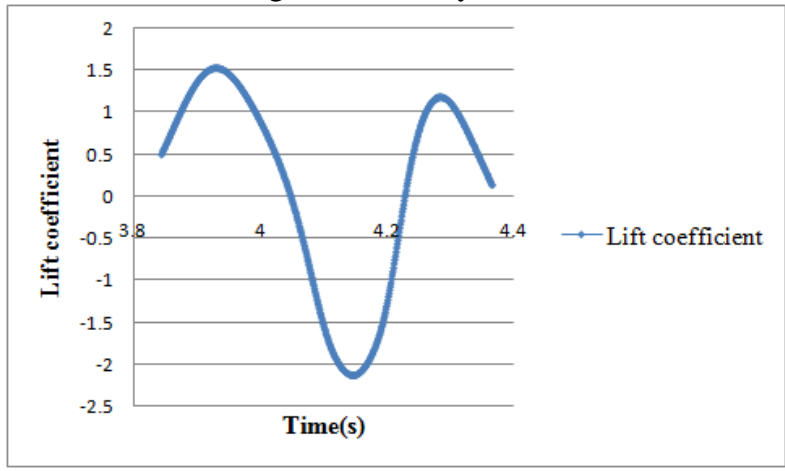

Fig. 15CL of cylinder

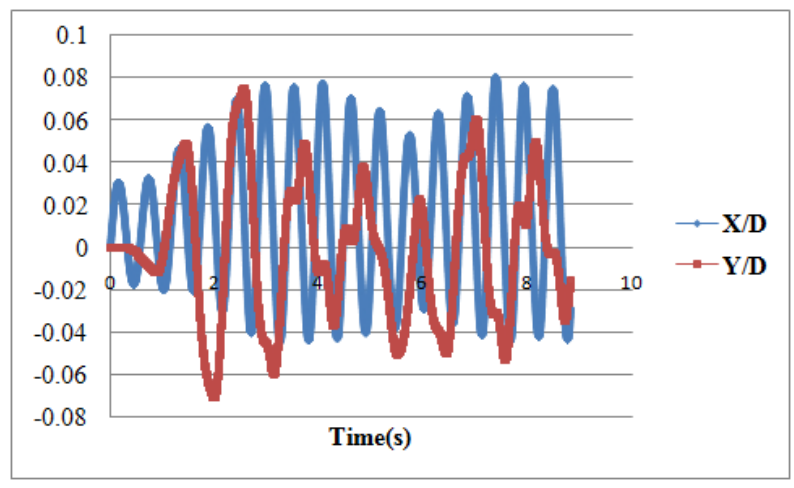

Fig. 16Motion response history of riser

\section{With 80 Pa internal pressure}

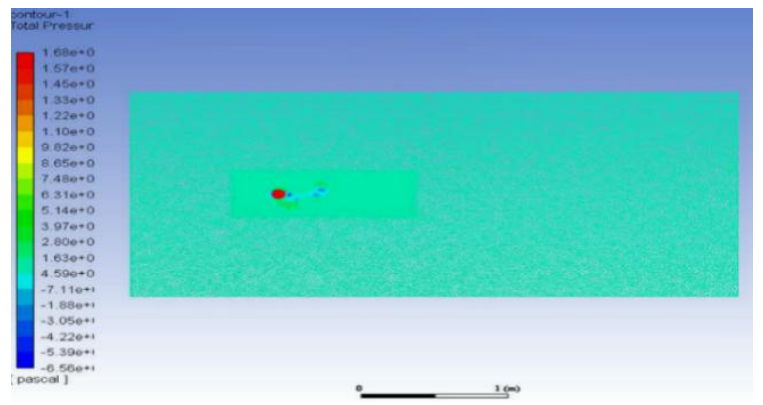

Fig. 17 Pressure contours of cylinder with internal pressure of $80 \mathrm{~Pa}$ 


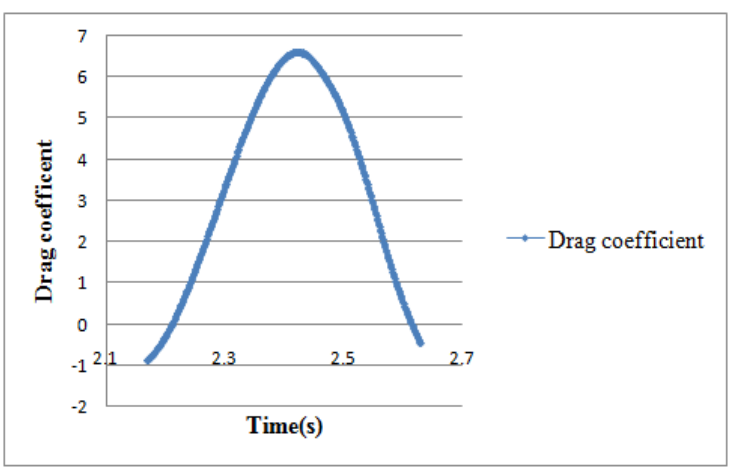

Fig. 18CD of cylinder

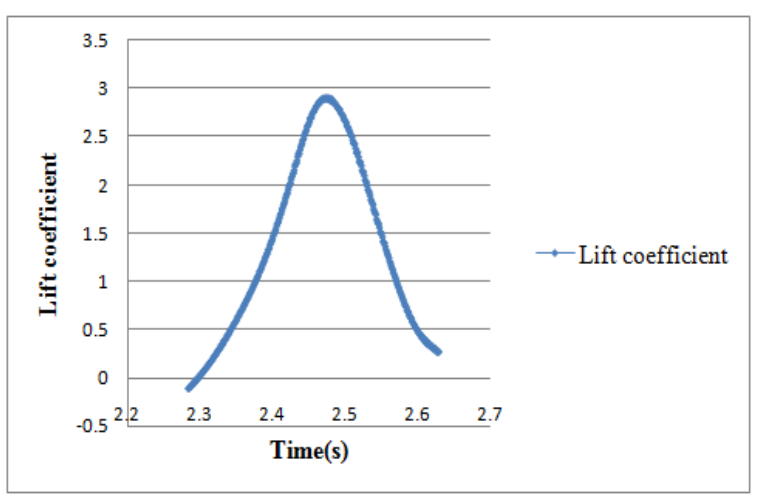

Fig. 19 CL of cylinder

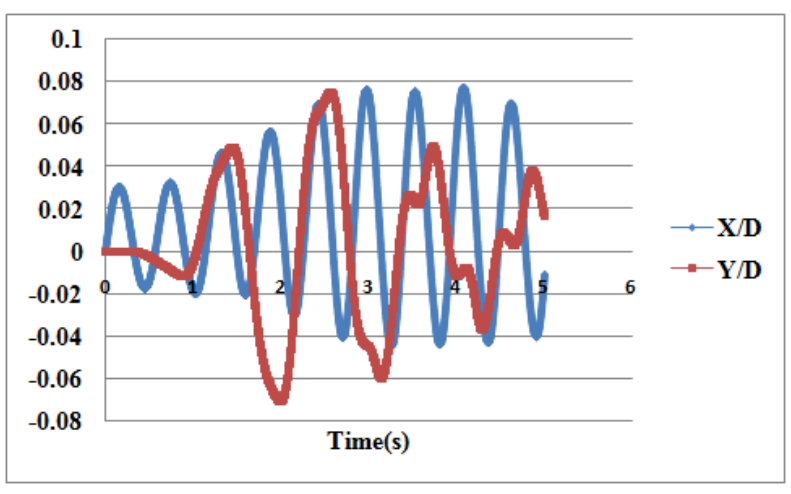

Fig. 20Motion response history of riser

The values of important hydrodynamic and structural parameters of both cases are shown in Table III.

\section{TABLE III}

Hydrodynamicand Structural Parameter Of Cylinder With Internal Pressure Variation

\begin{tabular}{|l|r|r|r|r|r|r|}
\hline TABLE & TAB & TAB & TAB & TAB & TAB & TA \\
RESSUR & D & L & CD & CL & MAX & MAX \\
\hline TABLE & TAB & TAB & TAB & TAB & TAB & TA \\
OPA & .34 & .99 & .60 & .60 & .08 & .05 \\
\hline
\end{tabular}

\begin{tabular}{|c|c|c|c|c|r|r|}
\hline TABLE & TAB & $\mathrm{TAB}$ & $\mathrm{TAB}$ & $\mathrm{TAB}$ & $\mathrm{TAB}$ & $\mathrm{TA}$ \\
OPA & .53 & .36 & .4 & .76 & .08 & .05 \\
\hline TABLE & $\mathrm{TAB}$ & $\mathrm{TAB}$ & $\mathrm{TAB}$ & $\mathrm{TAB}$ & $\mathrm{TAB}$ & $\mathrm{TA}$ \\
OPA & .09 & .28 & .91 & .91 & .08 & .06 \\
\hline TABLE & $\mathrm{TAB}$ & $\mathrm{TAB}$ & $\mathrm{TAB}$ & $\mathrm{TAB}$ & $\mathrm{TAB}$ & $\mathrm{TA}$ \\
OPA & .12 & .66 & .17 & .89 & .08 & .05 \\
\hline
\end{tabular}

Also, line graphs showing trends of drag and lift coefficients, frequencies and motion response were plotted for different pressure values.

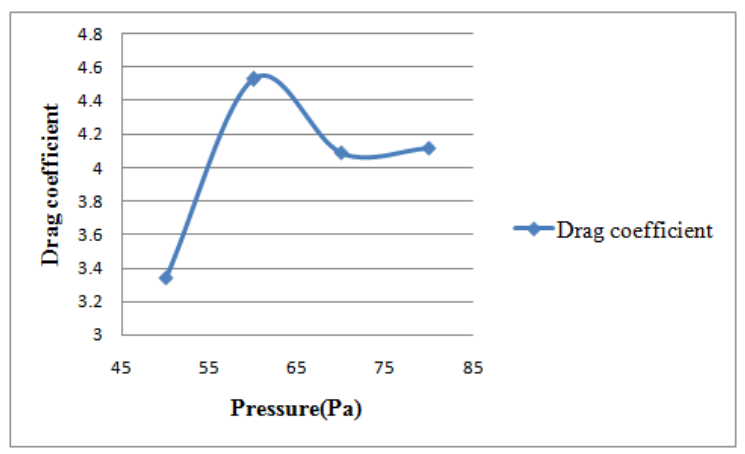

Fig.21CD of cylinder

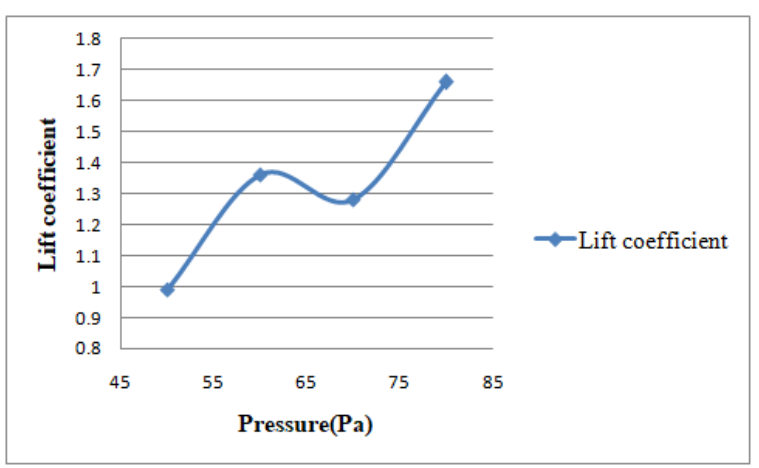

Fig. 22CL of cylinder

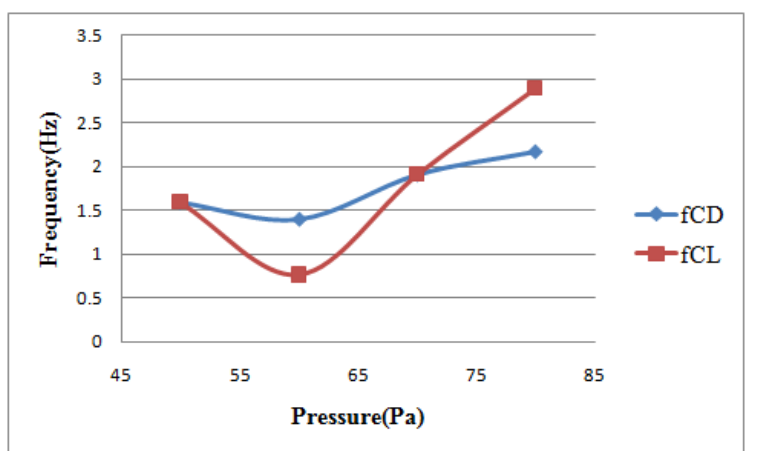

Fig. 23 Frequency of oscillation in inline and cross flow directions

Published By

Blue Eyes Intelligence Engineering \& Sciences Publication 


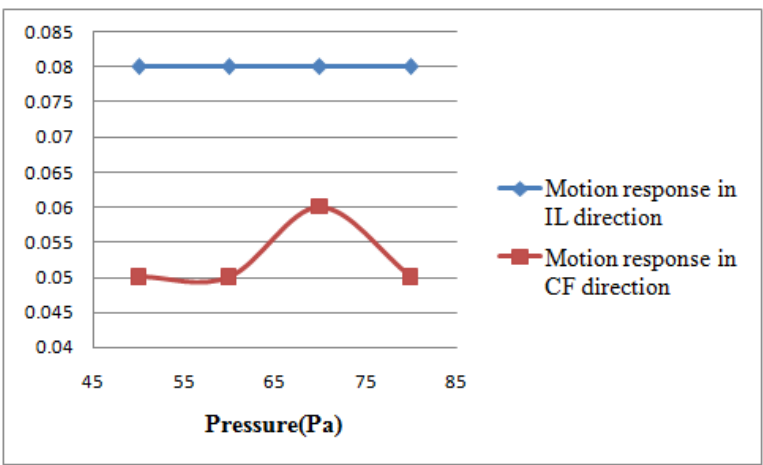

Fig. 24 Motion history in IL and CF directions

\section{CONCLUSIONS}

In the present work, a TDOF riser model with internal pressure variation was studied and the corresponding vortex shedding pattern was analyzed.Also, different hydrodynamic characteristics of riser like lift and drag forces were calculated in ANSYS FLUENT. The vortices evoked from behind the cylinder, at the wake portion was very much distinct in the case of riser without internal pressure. Drag coefficient showed a higher value for $60 \mathrm{~Pa}$ and lift coefficient was higher for $80 \mathrm{~Pa}$.The frequency of oscillations was calculated for one cycle and was found to increase with increase in fluid pressure. Also, at $70 \mathrm{~Pa}$ pressure, the cylinder shows a tendency to beat at a reduced velocity of $\mathrm{Ur}=5$ and a mass ratio of 0.55 . At $70 \mathrm{~Pa}$ pressure, the riser is observed to oscillate in the $\mathrm{CF}$ direction with a frequency equal to the vortex shedding frequency. As a result of which synchronization region is developed and together they resonate which results in failure of the riser system.

\section{FUTURE SCOPE}

The present work needs to be structurally analyzed for different hydrodynamic parameters and its corresponding deformation, stresses and strains under increase in fluid pressure values are to be calculated. Proper study on the structural response of a riser is necessary so as toincrease lifespan of the riser and to prevent fatigue damage of the structure.

\section{ACKNOWLEDGMENT}

I am thankful to SCMS School of Engineering and Technology and other members of Civil and Mechanical Engineering Department for their kind support and guidance offered for this study.

\section{REFERENCES}

1. Bernitsas M. M et al."Buckling of Risers in Tension due to Internal Pressure: Nonmovable Boundaries", Journal of Energy Resources Technology, Vol 105,pp: 277-281

2. Chandran, V, Sekar M, Janardhanan S, Menon V, "A numerical study on the influence of mass and stiffness ratios on the vortex induced motion of an elastically mounted cylinder for harnessing power", Energies, Vol 11,2580, pp:1-23, 2018.

3. Mao Liangjie, Liu Qingyou et al. "Vortex-induced vibration mechanism of drilling riser under shear flow", Petroleum exploration and development article, Vol 42, Issue 1, pp: 112-118, 2015.
4. Mao Liangjie, Liu Qingyou et al. "Experimental study of Vortex-induced vibration for drilling risers under uniform flow current",Journal of Vibro Engineering, Vol 19,Issue 2, pp:1392-8716, 2017.

5. Shuai Yuanet al. "Behavior of flexible pipe subjected to internal pressure"Proceedings of the ASME 2016 35th International Conference on Ocean, Offshore and Arctic Engineering,pp:1-10,2016.

6. Sup Hong, Jong-su Choi et al."Effects of internal flow on dynamics of underwater pipes", Proceedings of the Fifth Ocean Mining Symposium, pp: 91-97, 2003. 